\title{
Aged Zinc Oxide Nanoparticles Did Not Induce Cytotoxicity Through Apoptosis Signaling Pathway as Fresh NPs
}

\section{Juan Wang}

Anhui Medical University

Lei Wang

University of Miami

Wenting Zhao

Anhui Medical University

Meiling Cheng

Anhui Medical University

Mingqin Su

Anhui Medical University

Jian $\mathrm{Hu}$

Anhui Medical University

$\mathrm{Na} \mathrm{Yu}$

Anhui Medical University

Hua Du

Chinese Academy of Sciences

Meimei Wang ( $\nabla$ wangmm@ustc.edu.cn )

Anhui Medical University https://orcid.org/0000-0002-2671-9748

\section{Nano Express}

Keywords: zinc oxide nanoparticles, aging of nanoparticles, cytotoxicity, mechanism, apoptosis, transcriptomics

Posted Date: December 23rd, 2020

DOl: https://doi.org/10.21203/rs.3.rs-132318/v1

License: (c) (1) This work is licensed under a Creative Commons Attribution 4.0 International License.

Read Full License 
Version of Record: A version of this preprint was published at Nanoscale Research Letters on August 9th, 2021. See the published version at https://doi.org/10.1186/s11671-021-03587-y. 


\section{Abstract}

Zinc oxide nanoparticles (ZnO NPs) are being used in a wide range of applications including industry, commercial products and medicine field. Numerous mechanistic studies for ZnO NPs' toxicity are performed on pristine (fresh) NPs. However, the cytotoxicity induced by the transformed (aged) ZnO NPs and the underlying mechanisms remain unclear. Here, we firstly confirmed the physicochemical transformation of ZnO NPs underwent over time and compared the cytotoxicity induced by fresh and aged NPs. Then, we found that fresh NPs induced higher apoptosis levelthan aged NPs. Accordingly, RNA sequencing data from aged ZnO NP-treated human-hamster hybrid $\left(A_{\perp}\right)$ cells showed that p53, PI3k-Akt, FoXO, Glutathione, ErbB, HIF-1, Oxytocin and Jak-STAT signaling pathway were enriched but no apoptosis pathway. Quantitative PCR results confirmed the significantly higher mRNA level of IL 1B and CD69 in fresh NP-treated groups compared to that of aged ZnO NP- and zinc chloride-treated groups. Our data indicated that the lower cytotoxicity of aged ZnO NPs is closely related to the low level of apoptosis induced by it and that the transcriptional regulation of the multiple pathways activated by aged NPs helps to build the cellular homeostasis. Our results highlight the aging (environmental transformation) process to the toxicity and safety assessment of ZnO NPs.

\section{Introduction}

With the rapid development of nanotechnology over the last decades, nanoparticles (NPs) have been applied in various fields, including industry, human daily life and nanomedicine [1, 2]. The Nanotechnology Consumer Product Inventory (CPI) shows a 30-fold increase between 2005 and 2015 in the numbers of nano-products, including 762 health (fitness) products, 72 food (beverages), and 23 baby products [2].The growing application of NPs in consumer products and various fields increased the possibility of NPs entering into the environment, and raise safety concerns with regard to their potential adverse impacts.

Zinc oxide (ZnO) NPs are among the most commonly-used NPs, with a wide range of applications including, but not limited to, biomedical imaging, drug/ gene delivery, biosensing, and antibacterial/ antifungal applications [3]. The global annual output of ZnO NPs has reached nearly 3,400 tons [4]. Evidences have indicated that some substances previously considered as biologically inert could become toxic in their nanoparticulate state. An increasing number of studies have shown that ZnO NPs may pose significant risks to mammalian cells and animals by inducing significant toxicity [5-8].

Various strategies including coating, surface functionalization and oxidation state modification have been used to design NPs that could be biologically and environmentally safer. Each of these methods can target and prevent toxic mechanisms by modifying the physical and chemical properties of NPs (such as the dissolution, agglomeration and perturbation of cell membranes). These modifications ameliorate and in certain materials prevent toxic effects obviously. However, there are reports that that these design to increase the safety of NPswere not always effective under certain exposure conditions and environments [8-10]. Actually, many kinds of NPs are not stable and inclined to undergo "aging" or "environmental 
transformation" after being intentionally or unintentionally released into the natural environment [10-13]. In recent years, many researchers have carried out lots of work on the environmental transformation process of NPs, however, the research on the toxic effects of "transformed (aged)" NPs is still very limited, let alone their toxic mechanisms.

As a typical representative of non-persistent NPs, ZnO NPs have very high reactivity, and are prone to transform in physical and chemical properties and occurrence state after being released into the environment or ingested by animals and this change would significantly affect their toxicological effects $[13,14]$. For example, studies have shown that the sulfidation process of $\mathrm{ZnO}$ NPs changed the charge, hydrophobicity, and aggregation state, resulting in the adsorption of sulfide state NPs in human saliva, sweat, and bronchoalveolar lavage fluid. And the protein adsorbed by ZnO NPs forms a special protein crown, which affects its biological effect [15]. Phosphates in physiological solutions could convert ZnO NPs into metastable $\mathrm{ZnHPO}_{4}$ and $\mathrm{Zn}_{3}\left(\mathrm{PO}_{4}\right)_{2}$ within about 5-10 $\mathrm{h}$ [16]. The occurrence of complete transformation of $\mathrm{ZnO} N P s(\leq 3 \mu \mathrm{g} / \mathrm{mL})$ in the in vitro exposure system to human T lymphocytes $\left(37^{\circ} \mathrm{C}\right.$, cell culture medium RPMI 1640 containing $10 \%$ FBS for $24 \mathrm{~h}$ ) was investigated by using synchrotron radiation X-ray absorption near-edge structure spectroscopy (XANES) [17]. The above studies suggest that it is not enough to study pristine (fresh) NPs to assess their environmental and health risks. It is necessary to fully consider the aging and environmental transformation processes of NPs [18].

Our previous study unveiled that ZnO NPs aged for 40 to 120 days in ultrapure water underwent physicochemical transformation and turned into $\mathrm{Zn}_{5}\left(\mathrm{CO}_{3}\right)_{2}(\mathrm{OH})_{6}, \mathrm{Zn}(\mathrm{OH})_{2}$, and $\mathrm{Zn}^{2+}$ [19]. Interestingly, aged NPs exhibited lower cytotoxicity than fresh ZnO NPs [19], yet the toxicity mechanisms of such kind of variation are unclear. In the present study, we set out to explore the underlying reasons of different cytotoxicities between fresh and aged ZnO NPs. ZnO NPs with two different particle sizes $(20 \mathrm{~nm}$ and 90-200 nm) were applied systematically. The cytotoxicity assays demonstrated that aged ZnO NPs induced less pronounced morphological abnormalities and relatively higher cell viabilities than their fresh counterparts. RNA sequencing data revealed that apoptotic genes were enriched in fresh ZnO NP-treated cells, whereas these genes were much less affected by aged ZnO NP-treatments. In addition, the cells exposed to aged ZnO NPs showed reduced level of cleaved Caspase-3 protein, further indicating the higher potency of fresh ZnO NPs in eliciting apoptosis in cultured cells. Combined with our previous results, this study suggested that the decreased cytotoxicity of aged ZnO NPs is attributed to their attenuatedability in triggering cell apoptosis.

\section{Materials And Methods}

\section{Nanoparticles and Reagents}

The commercially available ZnO nanopowders (ZnO NPs), with manufacturer's reported average size 20 $\mathrm{nm}$ (99.5\% purity, nearly spherical) and $90-200 \mathrm{~nm}$ (99.9\% purity, irregular morphology), were purchasedfrom Nanostructured \& Amorphous Materials (Houston, TX). Except for otherwise noted, all the reagents and chemicals used in this study were purchased from Sigma-Aldrich (Shanghai, China). 


\section{Nanoparticle Dispersion, Aging and Characterization}

ZnO NPs stock suspensions ( $1 \mathrm{mg} / \mathrm{mL}$ ) were prepared by suspending dry nanopowders in Milli-Q $\mathrm{H}_{2} \mathrm{O}$ (Millipore, $18 \mathrm{M} \Omega \cdot \mathrm{cm}$ ), and sterilized by autoclaving $\left(120^{\circ} \mathrm{C}, 30 \mathrm{~min}\right)$, then stored at $25^{\circ} \mathrm{C}$ for natural aging period ranging from 0 to 60 days. The 0 -and 60-days' naturally transformed ZnO NPs were designated as fresh and aged NPs, respectively. To ensure proper dispersion, the fresh and aged suspensions were sonicated $(100 \mathrm{~W})$ for $30 \mathrm{~min}$ in an ultrasonic bath before characterization or incubation with cells. The morphology, particle size and aggregation of fresh and aged ZnO NPs were characterized by using transmission electron microscopy (TEM, JEOL JEM-2010, Tokyo, Japan). The crystal structure of fresh and aged ZnO NPs were determined using power X-ray diffraction (XRD, PANalytical B. V., Shanghai, China) by comparing to authentic standards. The details of natural aging process and characterization on ZnO NPs have been described previously [19].

\section{Cell Culture and Treatment with ZnO NPs}

$A_{L}$ cell line, a kind of human-hamster hybrid cells formed by fusion of the gly2A mutant of Chinese hamster ovary ( $\mathrm{CHO})$ and human fibroblasts, was used in this study. These hybrid cells contained a standard set of CHO-K1 chromosomes and a single copy of human chromosome 11, and were cultured in Ham's F12 medium (Hyclone, Grand Island, NY) supplemented with fetal bovine serum ( $8 \%$, Hyclone, Grand Island, NY), gentamicin $(25 \mathrm{~g} / \mathrm{mL})$ and glycine $\left(2 \times 10^{-4} \mathrm{M}\right)$ at $37^{\circ} \mathrm{C}$ in a humidified $5 \% \mathrm{CO}_{2}$ incubator [20].The stock suspensions of fresh and aged ZnO NPs were dispersed b y30 min of ultrasonication $(100 \mathrm{~W})$ to prevent agglomeration, subsequently diluted to appropriate concentrations with cell culturemedia for the exposure of cells. Cells maintained in cell culture media without NPs were served as control in each experiment.

\section{Assay for Detecting the Cytotoxicity}

$A_{L}$ cells at a logarithmic phase of growth were cultured on glass slides in 35-mm Petri dishes $\left(6 \times 10^{4}\right.$ cells/dish) for $24 \mathrm{~h}$ before stimulation, followed by treatment with $2 \mathrm{~mL}$ of culture medium containing 1 , $5,10,12,15$ and $20 \mu \mathrm{g} / \mathrm{mL}$ fresh or aged ZnO NPs $72 \mathrm{~h}$. After the completion of treatment time, the images of cell morphology were obtained using a Leica DM4B microscope (Leica, Germany). $\mathrm{ZnCl}_{2}$ was included as zinc ions reference for comparing the cytotoxicity with ZnO NPs.

The cell counting kit (CCK)-8 (APExBIO, Shanghai, China) was used for detecting the cell viability. In details, $A_{L}$ cells were seeded into 96 -well plates $\left(4 \times 10^{3}\right.$ cells/well $)$ with cell culture media for $24 \mathrm{~h}$, and treated with medium containing various concentrations of $\mathrm{ZnCl}_{2}$, fresh and aged $\mathrm{ZnO}$ NPs for 24, 48 and $72 \mathrm{~h}$, respectively. For working solution, the volume of added NPs from the stock suspension was less than $5 \%$ of the total volume of the culture medium in each well. After the completion of treatment time, the culture medium was aspirated, and the cells were incubated with $100 \mu \mathrm{L}$ CCK-8 working solution for 2 $\mathrm{h}$ at $37^{\circ} \mathrm{C}$ following the manufacturer's instructions. Then, the absorbance was recorded at $450 \mathrm{~nm}$ using a Spetra Max M2 fluorescence reader (Molecular Devices, Wokingham, Berks, UK).Cell viability was 
calculated as a percentage of absorbance in wells, with each concentration of NPs normalized to the absorbance of control cells (100\%).

\section{RNA Extraction, Reverse Transcription and Quantitative PCR}

$A_{L}$ cells at a logarithmic phase of growth were seeded into $35-\mathrm{mm}$ diameter Petri dish $\left(6 \times 10^{4} \mathrm{cells} / \mathrm{dish}\right)$ with cell culture media for $24 \mathrm{~h}$. Then the medium was replaced with $2 \mathrm{~mL}$ of culture medium containing $12 \mu \mathrm{g} / \mathrm{mL} \mathrm{ZnCl}_{2}$, fresh and aged $\mathrm{ZnO}$ NPs for $72 \mathrm{~h}$. After the completion of treatment time, the culture medium was aspirated, and cells were washed 3 times with PBS. Subsequently, $1 \mathrm{~mL}$ of Trizol reagent (Invitrogen, Carlsbad, CA, USA) was added to each dish to extract total RNA according to the manufacturer's instructions. Concentration and purity of total RNA obtained after the extraction were quantified usinga Q5000UV-Vis Spectrophotometer (Quawell, USA). After quantification, reverse transcription was performed using TransGene RT-PCR kit (TransGene Biotech, Beijing, China)to obtain cDNA from the RNA template according to the manufacturer's protocols.The resulting cDNA samples were quantified by usingthe Q5000 UV-Vis Spectrophotometer, and then analyzed using SYBR-Green as fluorescence dye (TransGene Biotech, Beijing, China) on Roche RT-PCR system (Applied Biosystems).

The housekeeping gene encoding Glyceraldehyde-3-phosphate Dehydrogenase (GAPDH) was used as internal control for evaluating II-1a, II-1 3 , Caspase 3, CD69, Jun and MT1 mRNA expression. The results were expressed as the relative expression ratio between the targeted gene and Gapdh. The primer sequences used in this study are provided in Table 1. 
Table 1

Primers used in this study

\begin{tabular}{|c|c|c|c|}
\hline Name & Primer & Sequence & Length (bp) \\
\hline \multirow[t]{2}{*}{$\|-1 a$} & Forward & 5' CGTCCGTCGTAATATCAG 3' & 178 \\
\hline & Reverse & 5'GACTTCATGGGACGATATG3' & \\
\hline \multirow[t]{2}{*}{$\|-1 \beta$} & Forward & 5' ACCTTCCAGGATGAGGACATGA3' & 121 \\
\hline & Reverse & 5'CTAATGGGAACGTCACACACCA3' & \\
\hline \multirow[t]{2}{*}{ Caspase 3} & Forward & 5'CACATGTTCTCTGGGAAATCG3' & 162 \\
\hline & Reverse & 5' TTGTATCTCTGGAAGTTTCAGATTGTT3' & \\
\hline \multirow[t]{2}{*}{ CD69 } & Forward & 5'GCCACCACGCTCTTCTGTCTAC3' & 163 \\
\hline & Reverse & 5' GGGTCTGGGCCATAGAACTGAT 3' & \\
\hline \multirow[t]{2}{*}{ Jun } & Forward & 5'CACATGTTCTCTGGGAAATCG3' & 177 \\
\hline & Reverse & 5' TTGTATCTCTGGAAGTTTCAGATTGTT3' & \\
\hline \multirow[t]{2}{*}{ MT1 } & Forward & 5'GCCACCACGCTCTTCTGTCTAC3' & 126 \\
\hline & Reverse & 5' GGGTCTGGGCCATAGAACTGAT 3' & \\
\hline \multirow[t]{2}{*}{ Gapdh } & Forward & 5'GTTAAGCAGTACAGCCCCAAA3' & 123 \\
\hline & Reverse & 5' AGGGCATATCCAACAACAAACTT3' & \\
\hline
\end{tabular}

\section{RNA Sequencing Data Analysis}

The total RNA samples of $A_{L}$ cells from control group, aged $\mathrm{ZnO}$ NP- treated group, and $\mathrm{ZnCl}_{2}$ treated group were sequenced by BangFei Bioscience (Beijing, China). Briefly, the total RNA of $A_{L}$ cells was extracted following the TRIZOL protocols, until the isoproponal precipitation. Then the RNA samples were resuspended in the extraction buffer before sequencing. The raw count RNA sequencing data was analyzed using R package Deseq2 [Eric1]. The venn diagram was generated by R package Venn Diagram [Eric1.2]. The significantly changed genes were used for further pathway enrichment analysis.

Experiments were done three independent replicates. rRNA genes, mitochondrial genes and the genes detected less than $40 \mathrm{bp}$ were excluded from the analysis.

The RNA sequencing data, reference series GSE97852, GSE60159, and GSE39444, were obtained from Gene Expression Omnibus [Eric2, 3, 4]. The Gene Set Enrichment Analysis plot was generated by R (version 3.6.2) using package fgsea [Eric5]. The apoptosis genes with 1.5-fold significant change \& $p$ value $<0.05$ were used for further analysis. The heatmap with gene tree was generated by $R$ package 
"Complex Heatmap" [Eric6]. Average linkage was used as the clustering method and Euclidean was used as a distance measurement method. The pathway enrichment analysis was preceded using STRING2.0 [Eric7].

\section{Western Blotting}

$A_{L}$ cells at a logarithmic phase of growth were seeded into 60 -mm diameter Petri dish $\left(1.5 \times 10^{5}\right.$ cells/dish) with cell culture media for $24 \mathrm{~h}$. Then the medium was replaced with $4 \mathrm{~mL}$ of culture medium containing $12 \mu \mathrm{g} / \mathrm{mL}$ fresh or aged ZnO NPs for $24 \mathrm{~h}$. At the end of exposure period, the culture medium was aspirated, and then cells were washed 3 times with PBS and lysed on ice with RIPA lysis buffer (Beyotime, China) to collect cellular proteins. Equal amounts of cellular proteins were separated on $12 \%$ SDS-PAGE gels, and then transferred to a polyvinylidene fluoride (PVDF) membrane (Roche, Swiss). Briefly, after $2 \mathrm{~h}$ blocking with $5 \%$ nonfat milk in TBST at $25^{\circ} \mathrm{C}$, the membranes were subsequently incubated with primary antibody at appropriate dilutions (according to the manufacturer's protocols) at $4^{\circ} \mathrm{C}$ overnight, followed by incubating with HRP-conjugated secondary antibodies (1:5000, Promega, Madison, USA) for $2 \mathrm{~h}$ at $25^{\circ} \mathrm{C}$.Finally, immunolabeling was detected using an enhanced chemiluminescence (ECL) (BOSTER, China) solution. The primary antibodies of anti-pro/cleaved Caspase3 and anti-Actin were purchased from Cell Signaling Technology and ImmunoWay, respectively.

\section{Statistics}

Statistical analysis was compiled on the means ofthe results obtained from at least three independent experiments. All Data were presented as means \pm standard deviation (SD), and statistically compared using one-way analysis of variance (ANOVA). In all plots $p$ values $<0.05$ were showed as * and considered to be statistically significant.

\section{Results}

\section{Characterization of ZnO NPs}

To determine the differences in detailed physicochemical characteristics between fresh and aged $\mathrm{ZnO}$ NPs, we first observed the morphology of NPs using a TEM (Fig. 1A). Our results indicated that $20 \mathrm{~nm}$ fresh ZnO NPs were nearly spherical crystals and 90-200 nm fresh ZnO NPs were irregularly rodlike/cubical crystals. The single particle size was consistent with the size provided by the manufacturer. Obviously, both $20 \mathrm{~nm} \&$ 90-200 nm ZnO NPs were inclined to aggregate in ultrapure water. Also, regardless of the shape and size of the original NPs, both $20 \mathrm{~nm}$ and 90-200 nm ZnO NPs' microstructure were dramatically changed from a clear crystal structure to an amorphous or sheet/needle-like state after aged for 60 days. Furthermore, the crystalline nature and phase purity of both fresh and aged NPs were determined by using X-ray diffraction (XRD) withCu Ka radiation $(\lambda=$ $0.15418 \mathrm{~nm}$ ) approach at $25^{\circ} \mathrm{C}$ and the obtained patterns were presented in Fig. 1B. The XRD pattern of fresh ZnO NPs indicated that the samples were comprised of crystalline wurtzite structure and no 
characteristic impurity peaks were identified, suggesting a high quality of fresh NPs. While the XRD pattern of aged NPs showed the neoformation of $\mathrm{Zn}_{5}\left(\mathrm{CO}_{3}\right)_{2}(\mathrm{OH})_{6}$ (card number 00-011-0287) and $\mathrm{Zn}$ $(\mathrm{OH})_{2}$ (card number 00-003-0888) solid phases, indicating the chemical transformation of ZnO NPs (20 and $90-200 \mathrm{~nm}$ ) during the aging process.

\section{Morphological Observation of $A_{L}$ cells Exposed to Fresh and Aged ZnO NPs}

NPs' treatment results in a noticeable change in cellular shape, or morphology, in vitro [21]. Therefore, $A_{L}$ cells exposed to fresh or aged $\mathrm{ZnO} N P s$ at $10 \& 15 \mu \mathrm{g} / \mathrm{mL}$ for $72 \mathrm{~h}$ were examined under a stereoscopic microscope. As shown in Fig. 2, cell morphology in the control group remained normal. The cells adhered well, with most attaching within $2 \mathrm{~h}$. Most cells were spindle-shaped or polygonal, with a few newly dividing cells showing a more transparent cytoplasm and better dispersion during the process of adhering. After treatment with $12 \mu \mathrm{g} / \mathrm{mL}$ fresh ZnO NPs (20 nm \& 90-200 nm) for $72 \mathrm{~h}$, cell morphology significantly changed. Although most cells adhered within 3-5h, they could not spread well, and some cells became rounded and lost the polygonal shape. When the concentration of ZnO NPs was increased to $15 \mu \mathrm{g} / \mathrm{mL}$, the treated cells atrophied and could not adhere; suggesting that cell viability was significantly lower than that of the cells treated with $10 \mu \mathrm{g} / \mathrm{mL}$. These results indicated that the LC100 for fresh ZnO NPs is mostly like less than $15 \mu \mathrm{g} / \mathrm{mL}$ when the treatment time is $72 \mathrm{~h}$. In contrast, cell morphology in $20 \mathrm{~nm}$ and $90-200 \mathrm{~nm}$ aged NP- treated groups $(15 \mu \mathrm{g} / \mathrm{mL})$ was not significantly different from that of the control groups, and most of the surviving cells could adhere and spread, with less than half dead cells observed, indicating aged ZnO NPs are much lower cytotoxicity than fresh ZnO NPs.

\section{Aged ZnO NPs Induced Lower Cytotoxicity than Fresh NPs}

To further investigate the difference in cytotoxicity between fresh and aged ZnO NPs, we examined the cell viability by using CCK-8 kits. As shown in Fig. 3 , incubation $A_{L}$ cells with graded doses of fresh and aged $\mathrm{ZnO} N P s$ (ranging from 0 to $20 \mu \mathrm{g} / \mathrm{mL}, 20 \mathrm{~nm}$ and $90-200 \mathrm{~nm}$ ) for $24 \mathrm{~h}, 48 \mathrm{~h}$, or $72 \mathrm{~h}$ showed a dose-dependent decrease of cell viability. At the dosages of $\mathrm{ZnO} \mathrm{NPs} \leq 10 \mathrm{mg} / \mathrm{mL}$, there was no observed cytotoxicity. But, when the dosage of fresh and aged ZnO NPs went up to 12 and $15 \mathrm{mg} / \mathrm{mL}$, the cell viability showed a time-dependent decrease tendency. Obviously, the cell viability in aged NP-treated groups was significantly higher than fresh NP-treated groups. In addition, the cell viability of $\mathrm{ZnCl}_{2}$-treated groups also showed a dose- and time-dependent decrease tendency. But, its cytotoxicity here was less than that of both fresh and aged ZnO NPs.

\section{Fresh ZnO NPs' Treatment Activated Apoptosis Pathways and Up-regulated the Expression of Apoptotic Genes}

To unveil the underlying mechanisms leading to the lower cytotoxicity of aged NPs, we analyzed RNA sequencing data from both fresh and aged ZnO NPs. As shown in Fig. 4A\&B, after treatment with fresh ZnO NPs, apoptosis pathway was significantly enriched in Jurkat cells $(p=0.017)$ and HMDM cells ( $p=$ 0.041). The apoptosis genes: ANXA1, CYLD, TNFSF10, IER3, CDKN1A, JUN, SAT1, PMAIP1, CD38, and 
ISG20 were significantly enriched in fresh ZnO NP- treated Jurkat cells. The apoptosis genes: $C D 38$, TNFRSF12A, CCNA1, BMP2, PPP2R5B, EREG, IFNGR1, CD44, CD14, GNA15, GCH1, TIMP1, BTG2, IL 1B, IL 1A, BTG3, BCL2L11, SC5D, and SPTAN1 were significantly enriched in fresh ZnO NP- treated HMDM cells (Fig. 4C \& D). Since Jurket cells (peripheral blood T lymphocyte cells) and HMDM cells (human monocyte-derived macrophages) belong to different kinds of cells, the way they trigger apoptosis might be different. Accordingly, the difference in activation of apoptosis pathway resulted in different apoptosis genes were activated. These results showed that fresh ZnO NPs' exposure could activate different apoptosis pathways in various kinds of cells.

\section{Aged ZnO NPs did not Up-regulate the Expression of Apoptotic Genes as Fresh ZnO NPs}

Our RNA sequencing data from aged ZnO NP- treated $A_{L}$ cells showed that p53, PI3k-Akt, FoXO, Glutathione, ErbB, HIF-1, Oxytocin, Jak-STAT signaling pathway were enriched (Fig. 5A). The apoptosis genes enriched in Jurket and HMDM cells were not significantly changed in expression in the aged ZnO NP- treated cells (Fig. 5B). To further confirm the findings, we tested the expression of related genes by real time PCR. We found that some of the apoptosis genes: BMP2, PMAIP1, IL 1a, CD69, CCNA1, CD38, and $I L 1 \beta$ were undetectable in aged $Z n O$ NPs-treated $A_{L}$ cells (data not shown), since most of these genes are expressed in immune system cells. The other apoptosis genes (IL $1 a, I L 1 \beta$, and $C D 59)$ with obviously increased expression level after fresh ZnO NPs' treatment were not significantly changed in expression in aged ZnO NP-treated $A_{L}$ cells. The $M T 1$, serve as a positive control, was significantly increased in expression as same as RNA-seq data. Also, the expression of Caspase 3 was not significantly changed (Fig. 5C). These data showed that fresh ZnO NPs activates apoptosis pathway genes in $A_{L}$ cells but not aged ZnO NPs.

\section{Fresh ZnO NPs (but not Aged NPs) Increased the Expression Level of the Activated Caspase3 Protein}

The change of expression for Caspase-3 at mRNA level could not directly reflect the activation of apoptosis pathway. To further analysis whether ZnO NPs' treatment could change apoptotic proteins' level, the expression of cleaved Caspase 3 protein was examined by western blotting analysis, considering the close relation between the activation of Caspase 3 and the apoptotic signaling pathways [22]. As shown by Fig. 6, compared to the control group, fresh ZnO NPs $(20 \mathrm{~nm})$ treatment increased the cellular level of cleaved Caspase 3 protein by $1.31 \pm 0.023$-fold, which was significantly higher than that of aged $20 \mathrm{~nm}$ ZnO NPs- treated group (1.12 \pm 0.039 -fold). When the particle size of fresh ZnO NPs was increased to $90-200 \mathrm{~nm}$, the expression of cleaved Caspase 3 protein induced by fresh NPs was increased by $1.46 \pm 0.078$-fold, significantly greater than that of aged NPs $(1.07 \pm 0.075$-fold).These data further illustrated the higher potency of fresh ZnO NPs in inducing cell apoptosis but not aged ZnO NPs.

\section{Discussion}


$\mathrm{ZnO} N P s$ was reported to underwent physicochemical transformation into $\mathrm{Zn}_{5}\left(\mathrm{CO}_{3}\right)_{2}(\mathrm{OH})_{6}$ with the release of $\mathrm{Zn}^{2+}$ during the natural aging process $[19,23]$. However, the cytotoxicity induced by the transformed (aged) ZnO NPs and the underlying possible mechanisms are unclear. Here, to unveil the mechanism of diverse cytotoxicity between fresh and aged ZnO NPs, RNA sequencing analysis and RTPCR test were conducted. Also, western blotting was applied to examine the protein level of Caspase3, the key executor in cell apoptosis.

Our data showed that aged ZnO NPs induced much less cytotoxicity than fresh ZnO NPs in $A_{L}$ cells. The $\mathrm{LC}_{100}$ of both fresh ZnO NPs (90-200 nm and $20 \mathrm{~nm}$ ) in our present study was lower than $15 \mathrm{mg} / \mathrm{mL}$ (Fig. 3), which was consistent with previous reporting that the $\mathrm{LC}_{100}$ of $\mathrm{ZnO} \mathrm{NPs}$ with $19-36 \mathrm{~nm}$ to NIH3 T3 or MSTO cell is about $15 \mathrm{mg} / \mathrm{mL}$ [24]. We confirmed that the environmental transformations of physicochemical properties in NPs are expected to dramatically alter their toxicity. It has been reported that the sulfidation process of ZnO NPs changed their charge, hydrophobicity, and aggregation state, resulting in the adsorption of sulfide state NPs in human saliva, sweat, and bronchoalveolar lavage fluid. And the protein adsorbed by ZnO NPs formed a special protein crown, which affected its biological effect [25]. Phosphates widely present in physiological solutions (such as saliva) could convert ZnO NPs into metastable $\mathrm{ZnHPO}_{4}$ and $\mathrm{Zn}_{3}\left(\mathrm{PO}_{4}\right)_{2}$ within about $5-10 \mathrm{~h}$, and showed cytotoxicity to digestive tract epithelial cells [16]. Ivasket al. proved the occurrence of complete transformation of ZnO NPs ( $\leq$ $3 \mu \mathrm{g} / \mathrm{mL})$ in the in vitro exposure system to human T lymphocytes $\left(37^{\circ} \mathrm{C}\right.$, cell culture medium RPMI1640 containing $10 \%$ FBS for $24 \mathrm{~h}$ ) using synchrotron radiation X-ray absorption near-edge structure spectroscopy (XANES). The spectrum and cytotoxicity of the transformation products were consistent with those of $\mathrm{ZnSO}_{4}$ [17]. Our results in this study showed that $\mathrm{ZnCl}_{2}$ is toxic to $A_{L}$ cells and the cell viability showed a dose- and time-dependent decrease tendency, but its cytotoxicity seems much lower than fresh and aged ZnO NPs (Fig. 3). It was consistent with the finding that $\mathrm{Zn}^{2+}$ released from ZnO NPs could not fully explain the toxicity fresh ZnO NPs to cells [26].

Our previous study also showed that aged ZnO NPs have an increase in size and ROS generation but significantly decreased cell death rate compared to fresh ZnO NPs [19]. Aged ZnO NPs caused less cytotoxicity and could be easier to adapt for the mammalian cells. The present study of RNA sequencing data illustrated that apoptotic genes have been up-regulated in fresh ZnO NP- treated cells, where they were much less affected in aged NP-treated groups. IL $1 \mathrm{a}$ and IL1 $\beta$ are members of the interleukin 1 cytokine family. The release of IL $1 \mathrm{a}$ and IL1 $\beta$ activates Caspase 8 partially dependent apoptosis [27]. CD69 encodes a member of the calcium-dependent lectin superfamily of type II transmembrane receptors. Increased CD69 expression was associated with an increased expression of the apoptosis annexin V and CD95 (Fas) marker [28]. JUN is an AP-1 Transcription Factor Subunit. Increased JUN activity proteolytically cleavage alpha-fodrin, a substrate of the interleukin 1 beta-converting enzyme (ICE), and CED-3 family of cysteine proteases, which further causes programmed cell death[29]. The increased expression of these apoptotic genes revealed that fresh NPs trigger apoptosis in several different ways. After the elevation of these apoptotic gene expressions, apoptosis processes are eventually executed by apoptotic proteins (Fig. 7). Caspase 3 is the core protease for various apoptotic scenarios, cleavage of 
this protein is necessary to activate both extrinsic and intrinsic apoptotic pathways [30,31]. Therefore, detection of cleaved caspase 3 is a common method for identifying apoptosis induced by a wide variety of apoptotic signals [32]. Our western blotting data revealed that, for both $20 \mathrm{~nm}$ and $90-200 \mathrm{~nm} \mathrm{ZnO}$ NPs, sublethal exposure did not alter the level of Pro caspase 3 in all treatment groups. In contrast, cleaved Caspase 3 was significantly elevated by fresh NPs treatment, where aged NPs showed few (if any) effects on the level of cleaved caspase 3 (Fig. 6). Combined with RNA expression analysis, our results clearly elucidated the higher potency of fresh ZnO NPs in inducing cell apoptosis.

\section{Conclusions}

In the present study, the natural physicochemical transformation of ZnO NPs in ultrapure water was confirmed, and variations in cytotoxicity induced by fresh \& aged NPs were investigated. We focused on RNA sequencing data from our aged ZnO NP-treated $A_{L}$ cells and that of fresh NPs from database. We compared those signaling pathway specifically enriched in aged NP-treated group, which are different from that of fresh NP- or $\mathrm{ZnCl}_{2}$ - treated groups. Our data indicated that the lower cytotoxicity of aged $\mathrm{ZnO}$

NPs is closely related to the low level of apoptosis induced by it and that the transcriptional regulation of the multiple pathways activated by NPs help the mammalian cells to build the cellular homeostasis.

\section{Declarations}

\section{Acknowledgements}

We would like to acknowledge the reviewers for their helpful comments on this paper.

\section{Author Contributions}

J.W., L.W. and M.M.W. performed the experiments. M.M.W., H.D., J.W., L.W., M.L.CH., M. Q. S.W.T.ZH. and N. Y. drafted the manuscript. M.M.W. and H.D. All authors read and approved the final manuscript.

\section{Funding}

This work was supported in part by grants from National Natural Science Foundation of China (22006149, 21507002 and 21677147), Anhui Provincial Natural Science Foundation (2008085MB49), "Hundred Talents Program" of the Chinese Academy of Sciences (E09BR22) and National undergraduate innovation and entrepreneurship training program (202010366043).

\section{Competing interests}

The authors declare that they have no competing financial interest.

\section{Availability of data and materials}

Not applicable 


\section{References}

1. Sohail, M.I.; Waris, A.A.; Ayub, M.A.; Usman, M.; Rehman, M.Z.; Sabir, M.; Faiz, T. Environmental application of nanomaterials: A promise to sustainable future. Comprehensive Analytical Chemistry 2019, 87, 1-54; DOI: 10.1016/bs.coac.2019.10.002.

2. Vance, M.E.; Kuiken, T.; Vejerano, E.P.; McGinnis, S.P.; Hochella, M.F.; Rejeski, D.; Hull, M.S. Nanotechnology in the real world: Redeveloping the nanomaterial consumer products inventory. Beilstein Journal of Nanotechnology 2015, 6, 1769-1780; DOI: 10.3762/bjnano.6.181.

3. Rajesh Kumar, S.; Lakshmi, T.; Naik, P. Recent advances and biomedical applications of zinc oxide nanoparticles. In Green Synthesis, Characterization and Applications of Nanoparticles; Elsevier: Amsterdam, The Netherlands, 2019, 445-457.

4. Keller, A.A.; Lazareva, A. Predicted releases of engineered nanomaterials: From global to regional to local. Environ. Technol. Lett. 2015, 1, 65-70; DOI: 10.1021/ez400106t.

5. George, S.; Pokhrel, S.; Xia, T.; Gilbert, B.; Ji, Z.X.; Schowalter, M.; Rosenauer, A.; Damoiseaux, R.; Bradley, K.A.; Madler, L., Nel; A.E. Use of a rapid cytotoxicity screening approach to engineer a safer zinc oxide nanoparticle through iron doping. ACS Nano 2010, 4 (1), 15-29; DOI: 10.1021/nn901503q.

6. Naatz, H.; Lin, S.J.; Li, R.B; Jiang, W.; Ji, Z.X.; Chang, C.H.; Koser, J.; Thoming, J.; Xia, T.; Nel, A.E. et al. Safe-by-Design $\mathrm{CuO}$ nanoparticles via Fe-doping, $\mathrm{Cu}-\mathrm{O}$ bond length variation, and biological assessment in cells and zebrafish embryos. ACS Nano 2017, 11 (1), 501-515; DOI: 10.1021/acsnano.6b06495.

7. Xia, T.; Kovochich, M.; Liong, M.; Mädler, L.; Gilbert, B.; Shi, H.; Yeh, J.I; Zink, J.I.; Nel, A.E. Comparison of the mechanism of toxicity of zinc oxide and cerium oxide nanoparticles based on dissolution and oxidative stress properties. ACS Nano 2008, 2 (10), 2121-2134; DOI: 10.1021/nn800511k.

8. Hwang, R.; Mirshafiee, V.; Zhu, YF.; Xia, T. Current approaches for safer design of engineered nanomaterials. Environ. Saf. 2018,166, 294-300; DOI: 10.1016/j.ecoenv.2018.09.077.

9. Bundschuh, M.; Filser, J.; Lüderwald, S.; McKee, M.S.; Metreveli, G.; Schaumann, G.E.; Schulz, R.; Wagner, S. Nanoparticles in the environment: where do we come from, where do we go to? Sci. Eur. 2018; 30(1), 6; DOI: 10.1186/s12302-018-0132-6.

10. Mortimer, M.; Holden, P.A. Fate of engineered nanomaterials in natural environments and impacts on ecosystems. Exposure to Engineered Nanomaterials in the Environment 2019, 61-103; DOI:10.1016/B978-0-12-814835-8.00003-0.

11. Mitrano, D.M.; Nowack, B. The need for a life-cycle based aging paradigm for nanomaterials: importance of real-world test systems to identify realistic particle transformation. Nanotechnology 2017, 28 (7), 072001; DOI: 10.1088/1361-6528/28/7/072001.

12. Mitrano, D.M.; Motellier, S.; Clavaguera, S.; Nowack, B. Review of nanomaterial aging and transformations through the life cycle of nano-enhanced products. Environment International 2015, 77, 132-147; DOI: 10.1016/j.envint.2015.01.013. 
13. Zhang, J.; Guo, W.L.; Li, Q.Q.; Wang, Z.; Liu, S.J. The effects and the potential mechanism of environmental transformation of metal nanoparticles on their toxicity in organisms. Environmental science: Nano 2018, 5 (11), 2482-2499; DOI: 10.1039/c8en00688a.

14. Odza, N.; Kistler, D.; Sigg, L. Influence of daylight on the fate of silver and zinc oxide nanoparticles in natural aquatic environments. Pollut. 2017, 226, 1-11; DOI: 10.1016/j.envpol.2017.04.006.

15. Du, T.T.; Shi, G.L.; Liu, F.F.; Zhang, T.; Chen, W. Sulfidation of Ag and ZnO Nanomaterials Significantly Affects Protein Corona Composition: Implications for Human Exposure to Environmentally Aged Nanomaterials. Sci. Technol. 2019, 53 (24), 14296-14307; DOI: 10.1021/acs.est.9b04332.

16. David, C.A.; Galceran, J.; Quattrini, F.; Puy, J.; Rey-Castro, C. Dissolution and phosphate-induced transformation of $\mathrm{ZnO}$ nanoparticles in synthetic saliva probed by AGNES without previous solidliquid separation. Comparison with UF-ICP-MS. Sci. Technol. 2019, 53 (7), 3823-3831; DOI: 10.1021/acs.est.8b06531.

17. Ivask, A.; Scheckel, K.G.; Kapruwan, P.; Stone, V.; Yin, H.; Voelcker, N.H.; Lombi, E. Complete transformation of $\mathrm{ZnO}$ and $\mathrm{CuO}$ nanoparticles in culture medium and lymphocyte cells during toxicity testing. Nanotoxicology 2017, 11 (2), 150-156; DOI: 10.1080/17435390.2017.1282049.

18. Nowack, B.; Ranville, J.F.; Diamond, S.; Gallego-Urrea, J.A.; Metcalfe, C.; Rose, J.; Horne, N.; Koelmans, A.A.; Klaine, S.J. Potential scenarios for nanomaterial release and subsequent alteration in the environment. Toxicol. Chem. 2012, 31(1), 50-59; DOI: 10.1002/etc.726.

19. Wang, M.M.; Wang,Y.C.; Wang, X.N.; Liu,Y.; Zhang, H.; Zhang, J.W.; Huang, Q.; Chen, S.P.; Hei, T.K.; Wu L.J.; Xu, A. Mutagenicity of ZnO Nanoparticles in Mammalian Cells: Role of Physicochemical Transformations under the Aging Process, Nanotoxicology 2015, 9, 972; DOI: 10.3109/17435390.2014.992816.

20. Hei, T.K.; Liu, S.X.; Waldren, A. Mutagenicity of arsenic inmammalian cells: role of oxygen reactive species. Natl. Acad. Sci. 1998, 95, 8103-8107; DOI: 10.1073/pnas.95.14.8103.

21. Song, Y.J.; Guan, R.F.; Lyu, F.; Kang, T.S.; Wu, Y.H.; Chen, X.Q. In vitro cytotoxicity of silver nanoparticles and zinc oxide nanoparticles to human epithelial colorectal adenocarcinoma (Caco-2) cells. Mutation Research-Fundamental and Molecular Mechanisms of Mutagenesis 2014, 769, 113118; DOI: 10.1016/j.mrfmmm.2014.08.001.

22. Budihardjo, I.; Oliver, H.; Lutter, M.; Luo, X.; Wang, X.D. Biochemical pathways of caspase activation during apoptosis. Annu Rev Cell Dev Bi.1999, 15, 269-290; DOI: 10.1146/annurev.cellbio.15.1.269.

23. Zhang, H.; Huang, ; Xu, A.; Wu, L.J. Spectroscopic probe to contribution of physicochemical transformations in the toxicity of aged ZnO NPs to Chlorella vulgaris: new insight into the variation of toxicity of ZnO NPs under aging process, Nanotoxicology 2016, 10(8), 1177-1187; DOI: 10.1080/17435390.2016.1196252.

24. Brunner, T.J.; Wick, P.; Manser, P.; Spohn, P.; Grass, R.N.; Limbach, K.; Bruinink, A.; Stark, W.J.In vitro cytotoxicity of oxide nanoparticles: comparison to asbestos, silica, and the effect of particle solubility. Environ. Sci. Technol. 2006, 40, 4374-4381; DOI: 10.1021/es052069i. 
25. Du, T.T.; Shi, G.L.; Liu, F.F.; Zhang, T.; Chen, W. Sulfidation of Ag and ZnO Nanomaterials Significantly Affects Protein Corona Composition: Implications for Human Exposure to Environmentally Aged Nanomaterials. Sci.Technol. 2019, 53 (24), 14296-14307; DOI: 10.1021/acs.est.9b04332.

26. Raghupati, K.R.; Koodaali, R.T.; Manna, A.C. Size dependent bacterial growth inhibition and mechanism of antibacterial activity of zinc oxide nanoparticles. Langmuir 2011, 27, 4020-4028; DOI: $10.1021 /$ la104825u.

27. England, H.; Summersgill, H.; Edye, M.; Rothwell, N.; Brough, D. Release of Interleukin-1a or Interleukin$1 \beta$ Depends on Mechanism of Cell Death. J. Biol. Chem.2014, 289, 15942-15950; DOI:10.1074/jbc.M114.557561.

28. Meier, Pascal.खD ayer, E.; Blanc, E.; Wauters, J.P. Early T cell activation correlates with expression of apoptosis markers in patients with end-stage renal disease. J. Am. Soc. Nephrol. 2002, 13(1), 204212; DOI: 10.1053/jren.2002.31185.

29. Bossy-Wetzel, E.; Bakiri, L.; Yaniv, M. Induction of apoptosis by the transcription factor C-Jun.EMBO J.1997, 16(7), 1695-1709; DOI: 10.1093/emboj/16.7.1695.

30. Elmore, S. Apoptosis: a review of programmed cell death. Toxicol.Pathol.2007, 35(4), 495-516; DOI: 10.1080/01926230701320337.

31. Shalini, S.; Dorstyn, L.; Dawar, S.; Kumar, S. Old, new and emerging functions of caspases. Cell Death. Differ. 2015, 22(4), 526-539; DOI: 10.1038/cdd.2014.216.

32. Choudhary, G.S.; Al-Harbi, S.; Almasan, A. Caspase-3 activation is a critical determinant of genotoxic stress-induced apoptosis. Methods. Mol. Biol. 2015, 1219, 1-9. DOI: 10.1007/978-1-4939-1661-0_1.

\section{Figures}

(A)

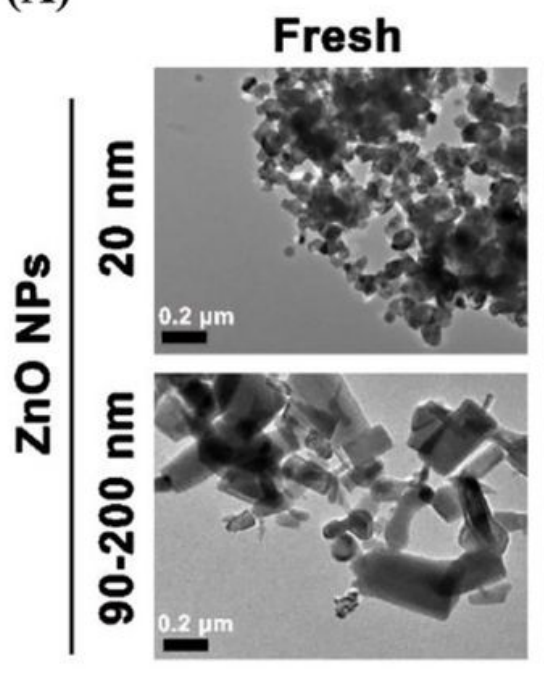

(B)

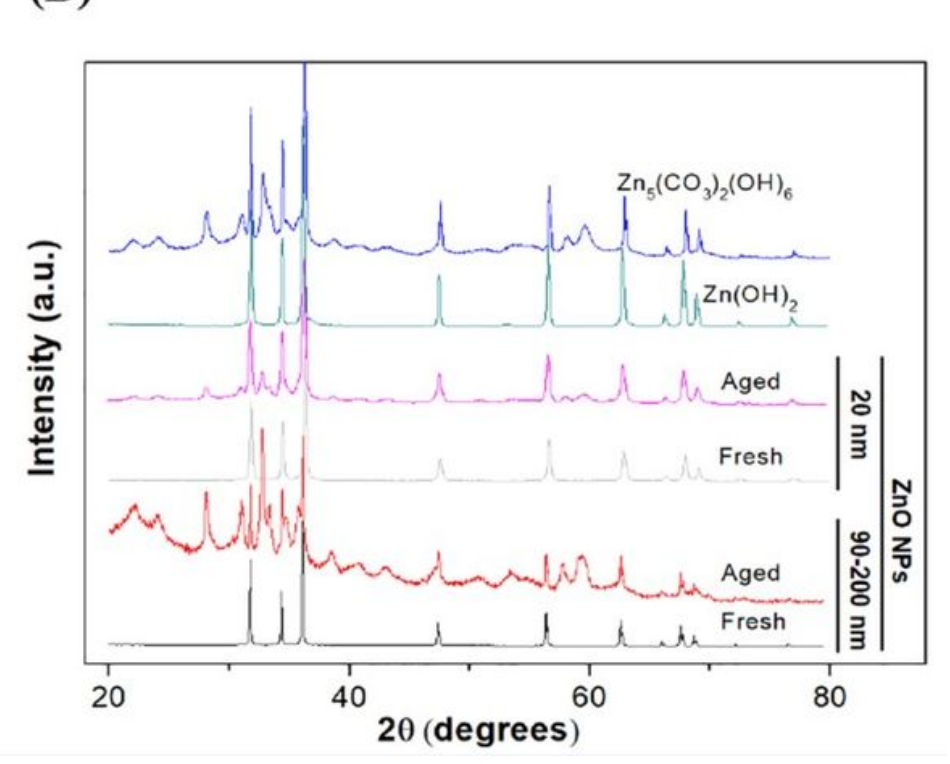

\section{Figure 1}

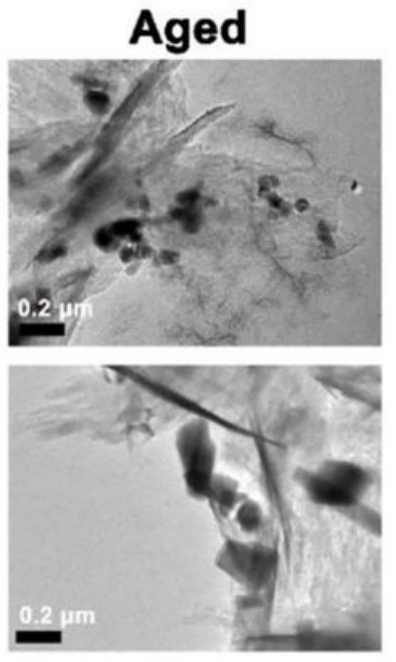


Physicochemical characteristics of fresh and aged ZnO NPs. (A) Representative micrographs of fresh and aged NPs (100 $\mu \mathrm{g} / \mathrm{mL}, 20$ and 90-200 nm) in Milli-Q water using low resolution TEM, (B) XRD patterns of fresh NPs, aged NPs, $\mathrm{Zn}(\mathrm{OH}) 2$ and $\mathrm{Zn} 5(\mathrm{CO} 3) 2(\mathrm{OH}) 6$ references in dried form.

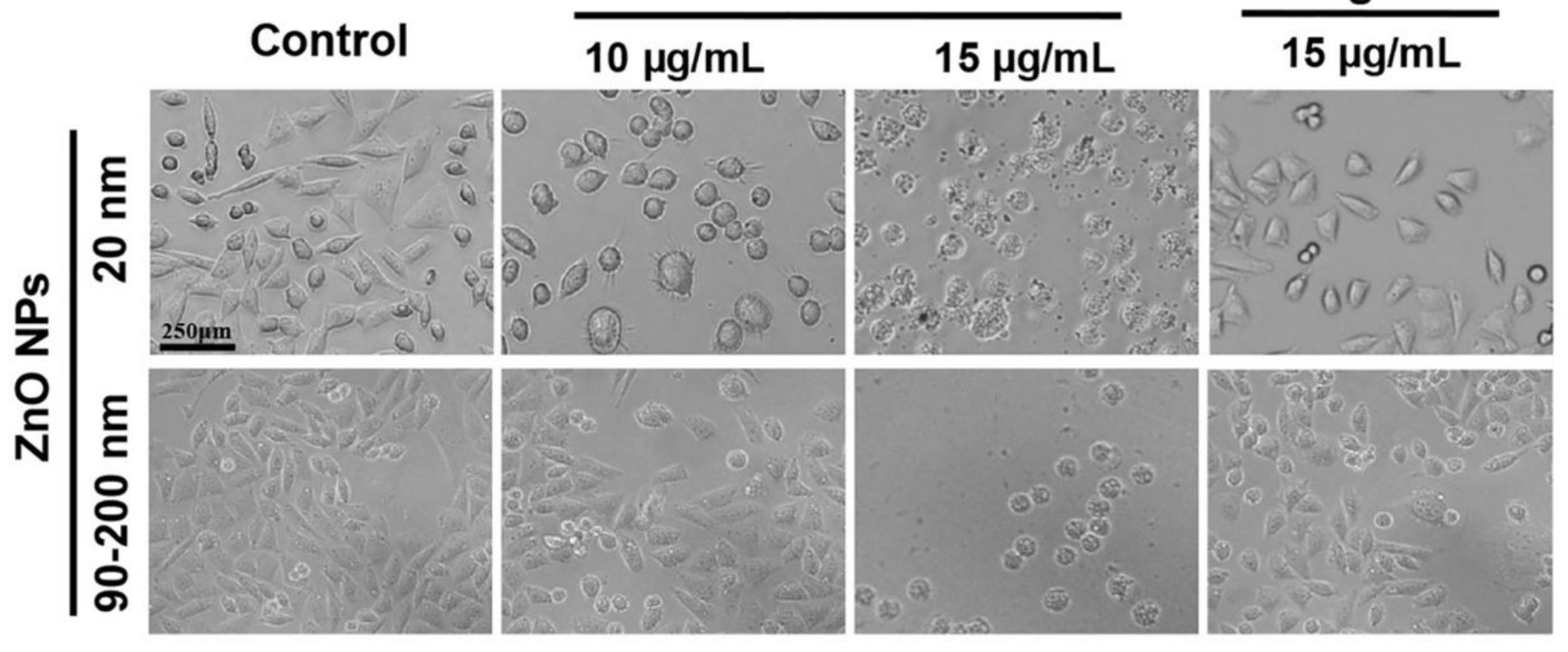

Figure 2

Morphology changes in AL cells after exposure to fresh or aged ZnO NPs for $72 \mathrm{~h}$ in supplemental Ham's F12 medium, and unexposed cells were used as control groups. AL cell morphology was observed with an optical microscope at $10 \times$ magnification. 
(A)

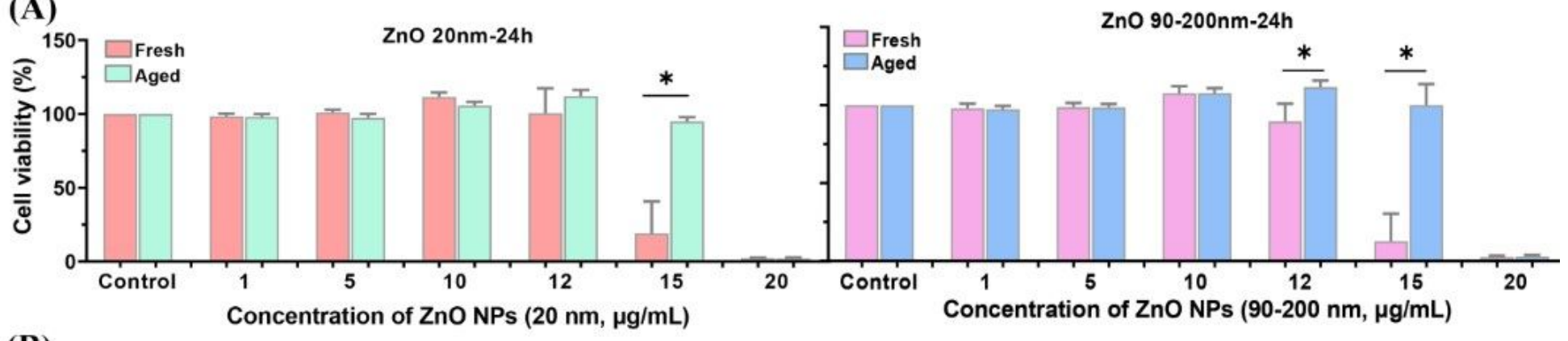

(B)

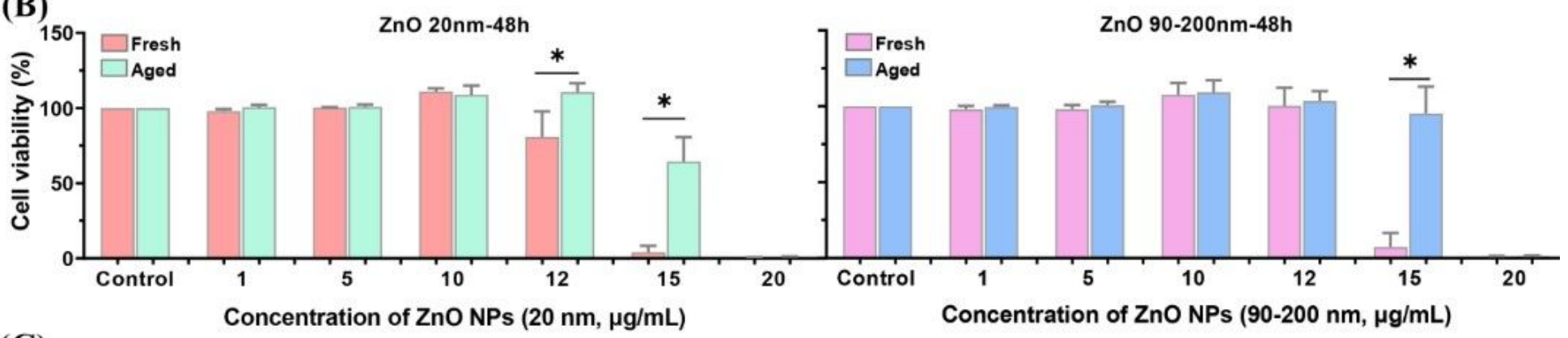

(C)

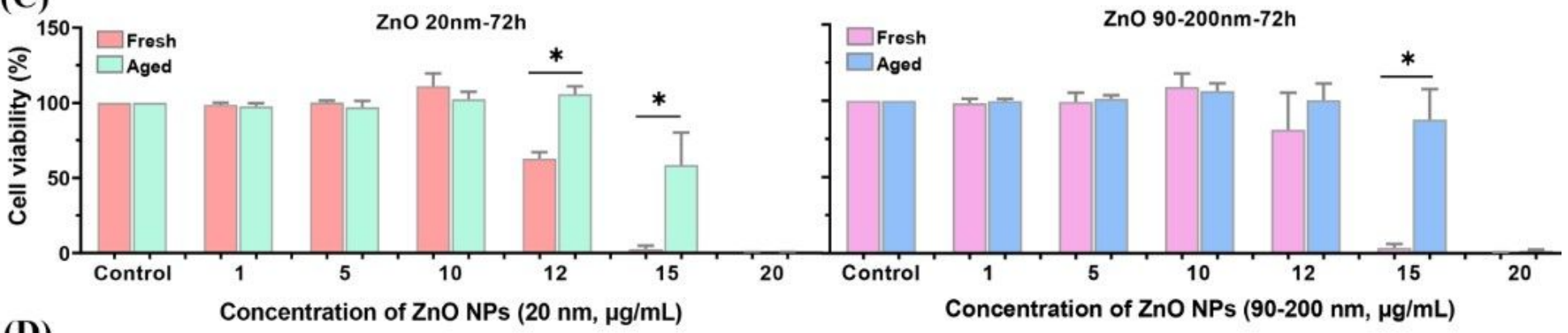

(D)

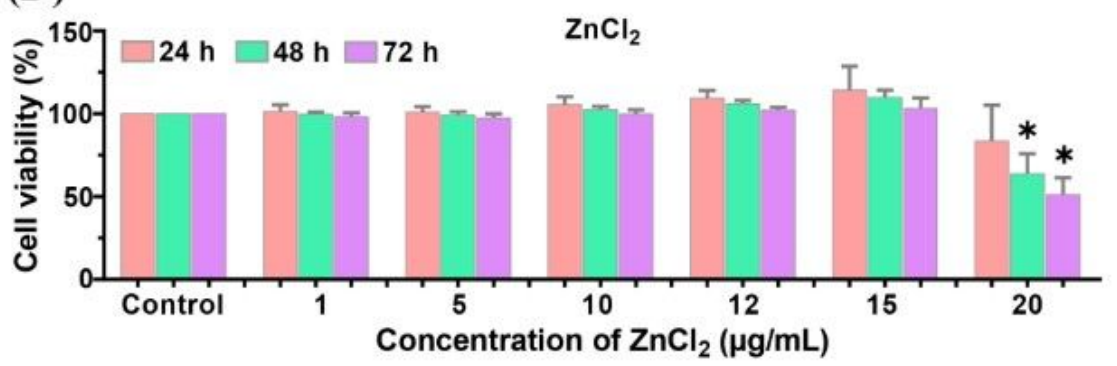

Figure 3

Cell viability induced by fresh and aged ZnO NPs in AL cells. AL cells were incubated with various concentrations of fresh and aged ZnO NPs $(20$ and 90-200 nm) for $24 \mathrm{~h} \mathrm{(A),} 48 \mathrm{~h}$ (B) and $72 \mathrm{~h}$ (C). (D) AL cells were exposed to various concentrations of $\mathrm{ZnCl} 2$ for different times. Data were based on $\geq 3$ independent experiments and expressed as mean $\pm S D$, * $p<0.05$. 
(A)

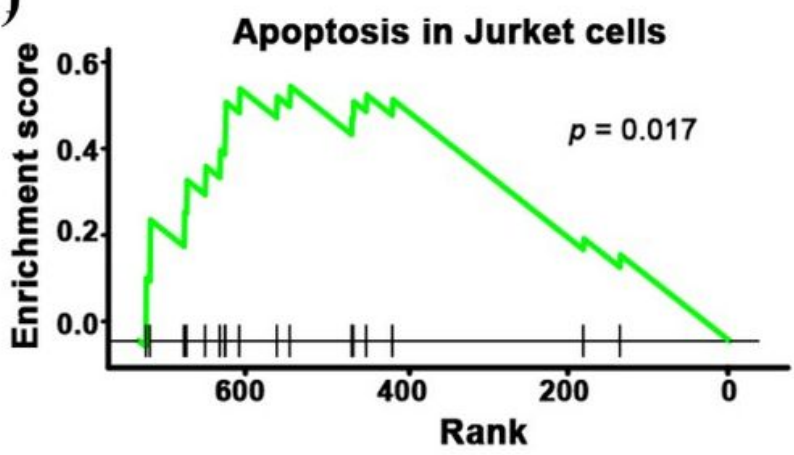

(C)

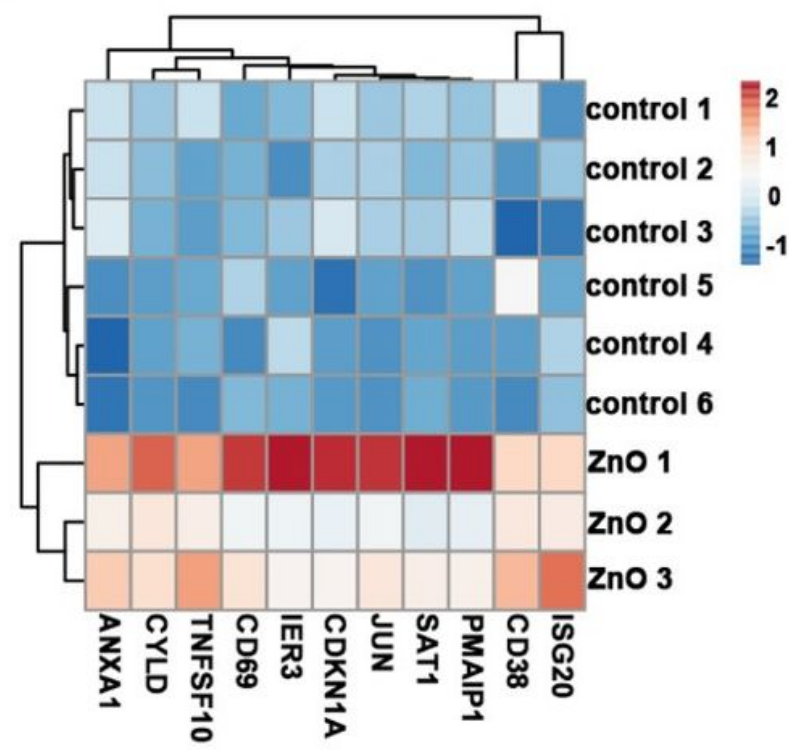

(B)

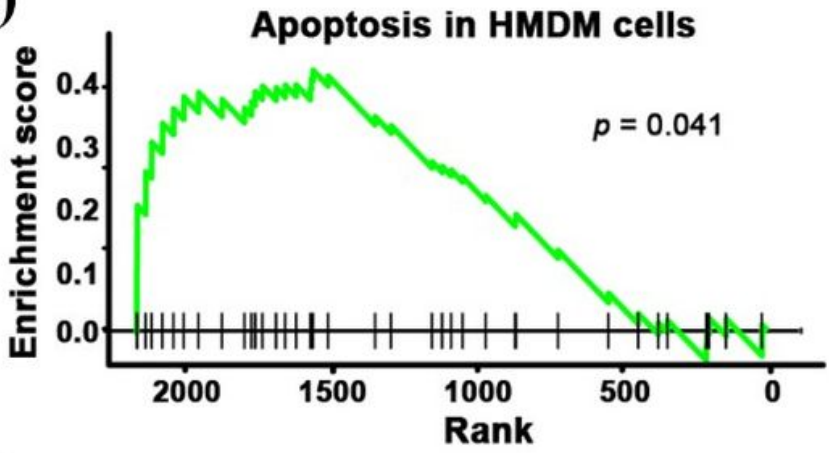

(D)

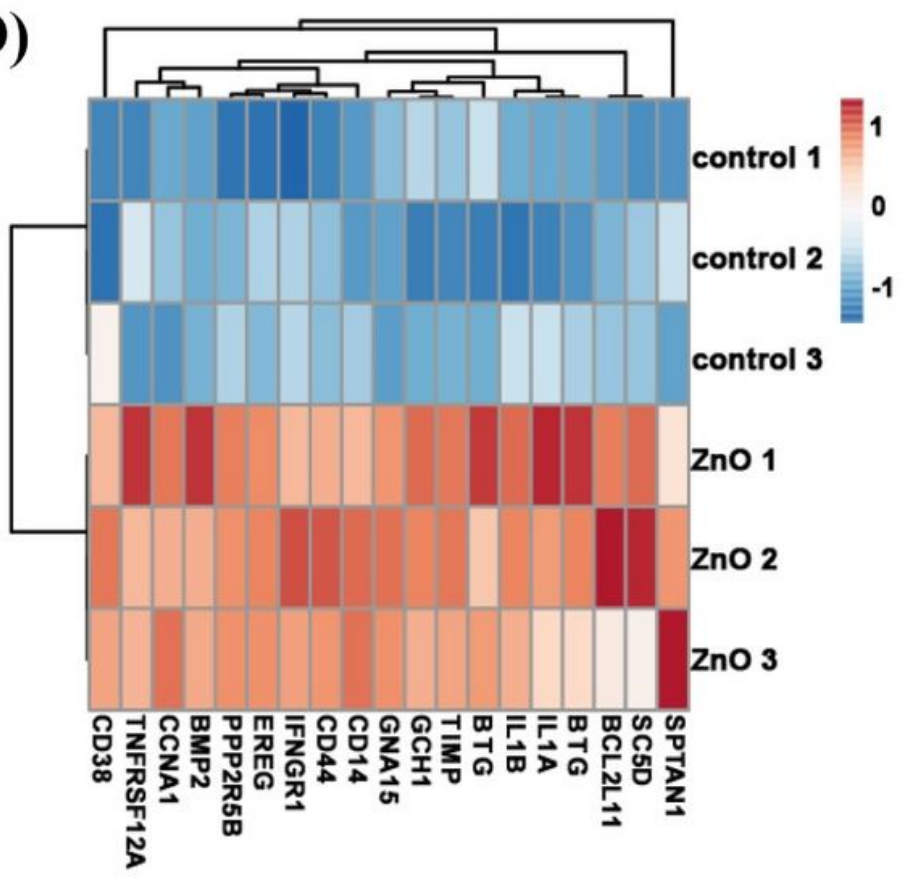

Figure 4

The apoptosis pathway was enriched in RNA-seq data of fresh ZnO NP-treated Jurket and HMDM cells. The enrichment score of significantly expressed genes from apoptosis pathway of fresh ZnO NP- treated Jurket cells (A) and HMDM cells (B). The heatmap of apoptotic gene expression of fresh ZnO NP- treated Jurket cells (C) and HMDM cells (D) and their control groups. 
(A) $-\log 10 \mathrm{FDR}$

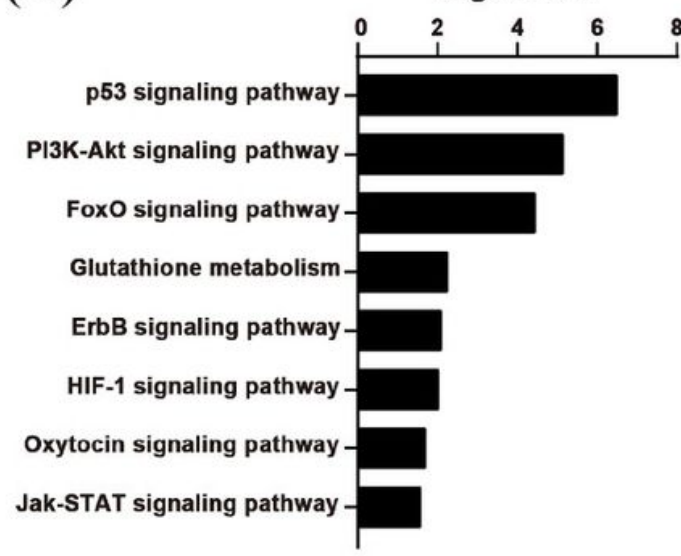

(B)

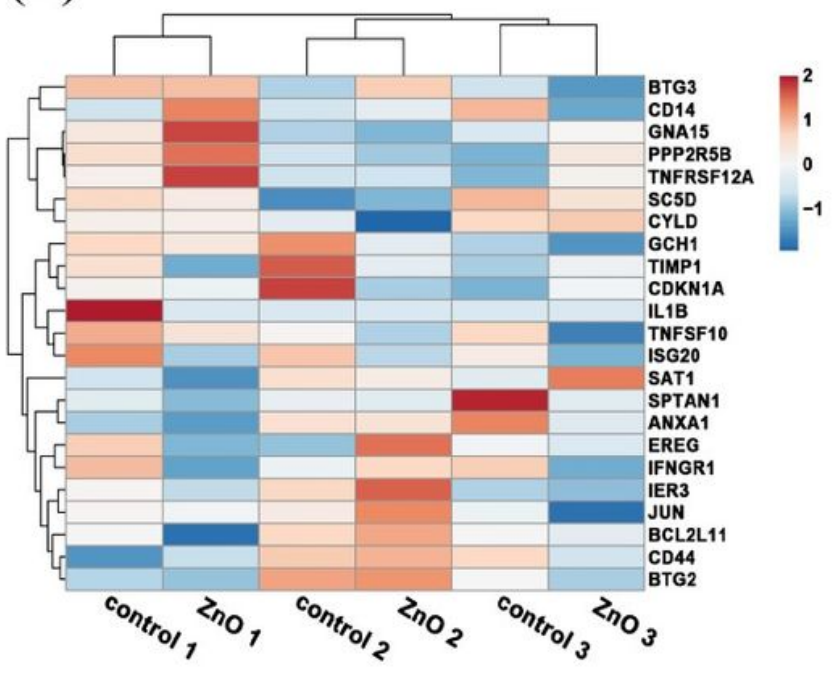

(C)

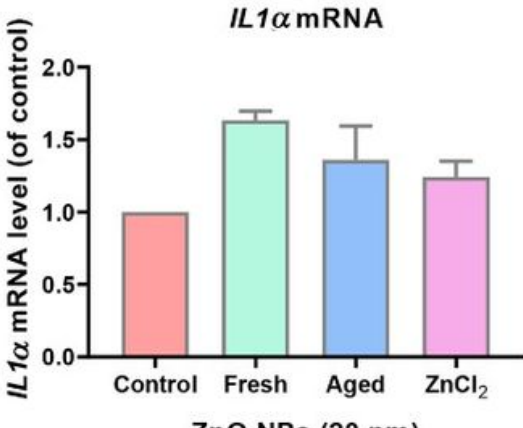
ZnO NPs $(20 \mathrm{~nm})$

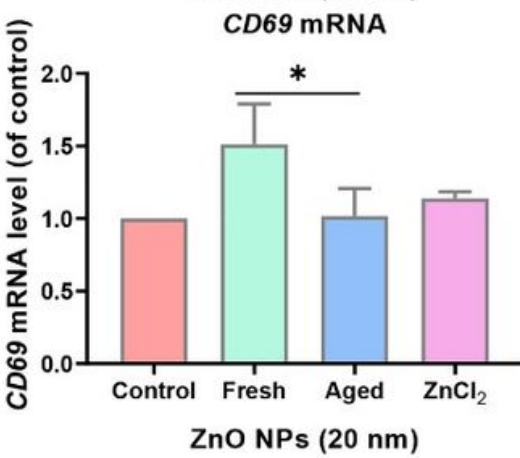

JUN mRNA

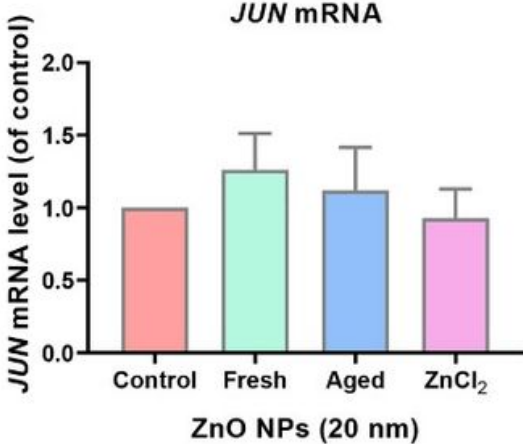

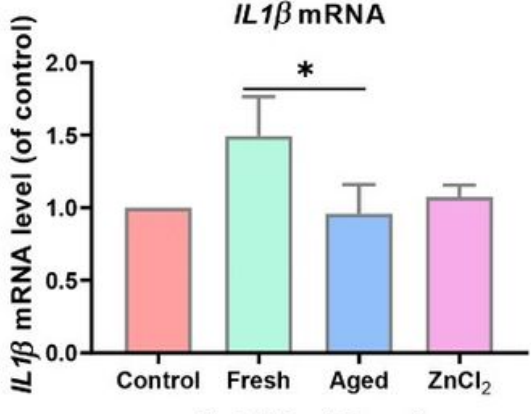

ZnO NPs $(20 \mathrm{~nm})$

Caspase 3 mRNA

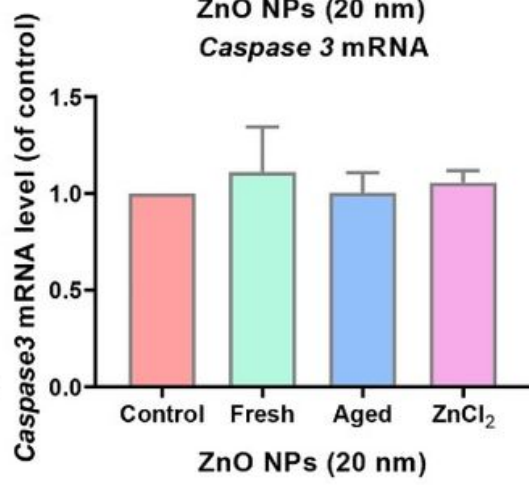

MT1 mRNA

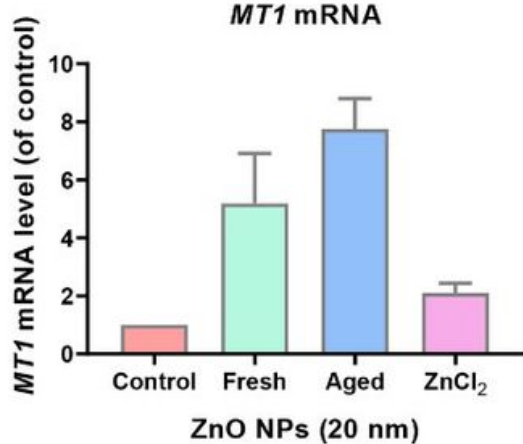

Figure 5

The apoptosis pathway was not enriched in RNA-seq data of aged ZnO NPs- treated AL cells. (A) The gene ontology analysis of enriched pathways from aged ZnO NPs- treated AL cells. (B) The heatmap of apoptotic gene expression of aged ZnO NPs- treated AL cells and control group. (C) The expression of selected apoptotic genes and control genes (MT1) in fresh and aged ZnO NPs- treated AL cells. 
(A)

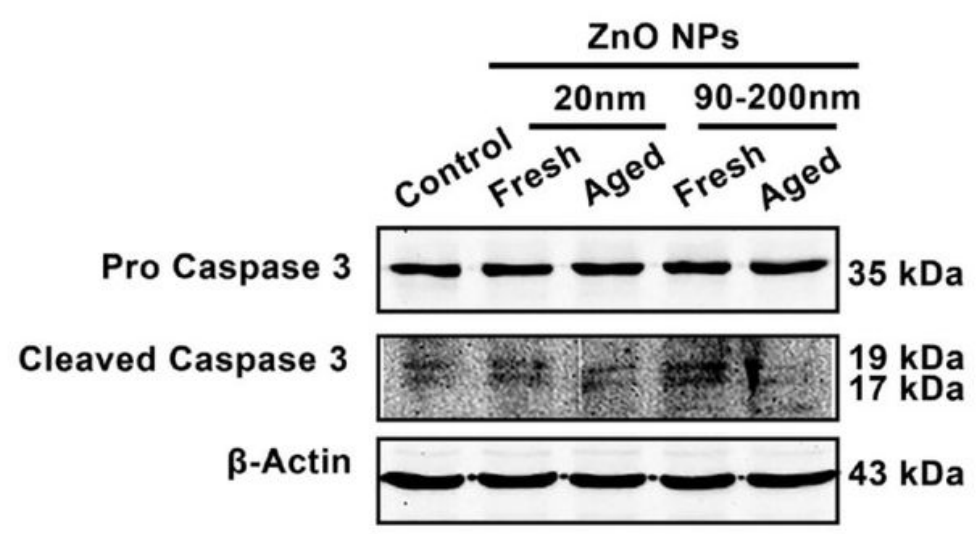

(B)

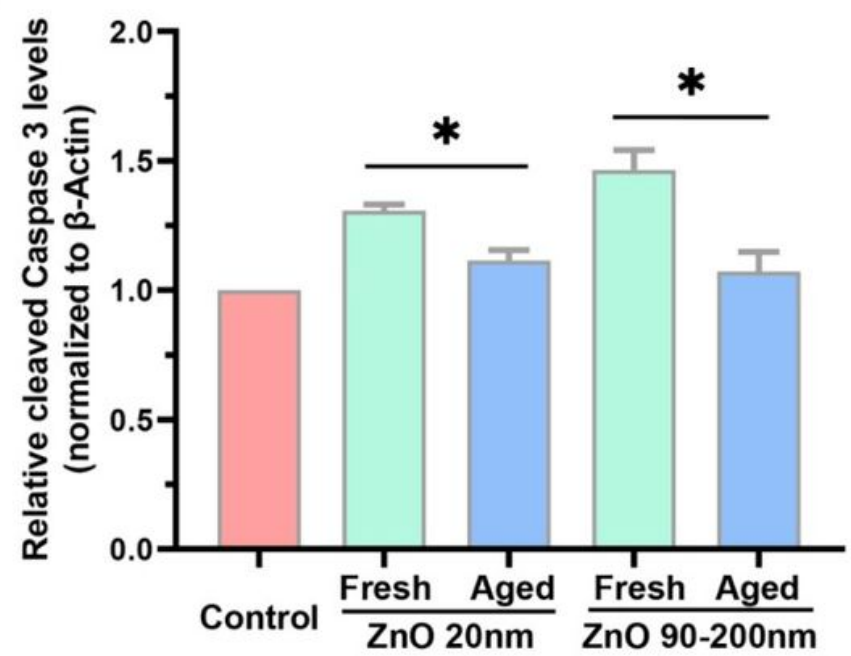

Figure 6

Apoptotic levels in AL cells incubated with fresh and aged ZnO NPs (20 and 90-200 nm). Western Blotting analysis (A) and quantification (B) of cleaved Caspase 3 protein levels when cells were incubated with 12 $\mu \mathrm{g} / \mathrm{ml}$ fresh and aged ZnO NPs (20 and $90-200 \mathrm{~nm}$ ) for $72 \mathrm{~h}$. Data were based on $\geq 3$ independent experiments and expressed as mean $\pm S D,{ }^{*} p<0.05$. 


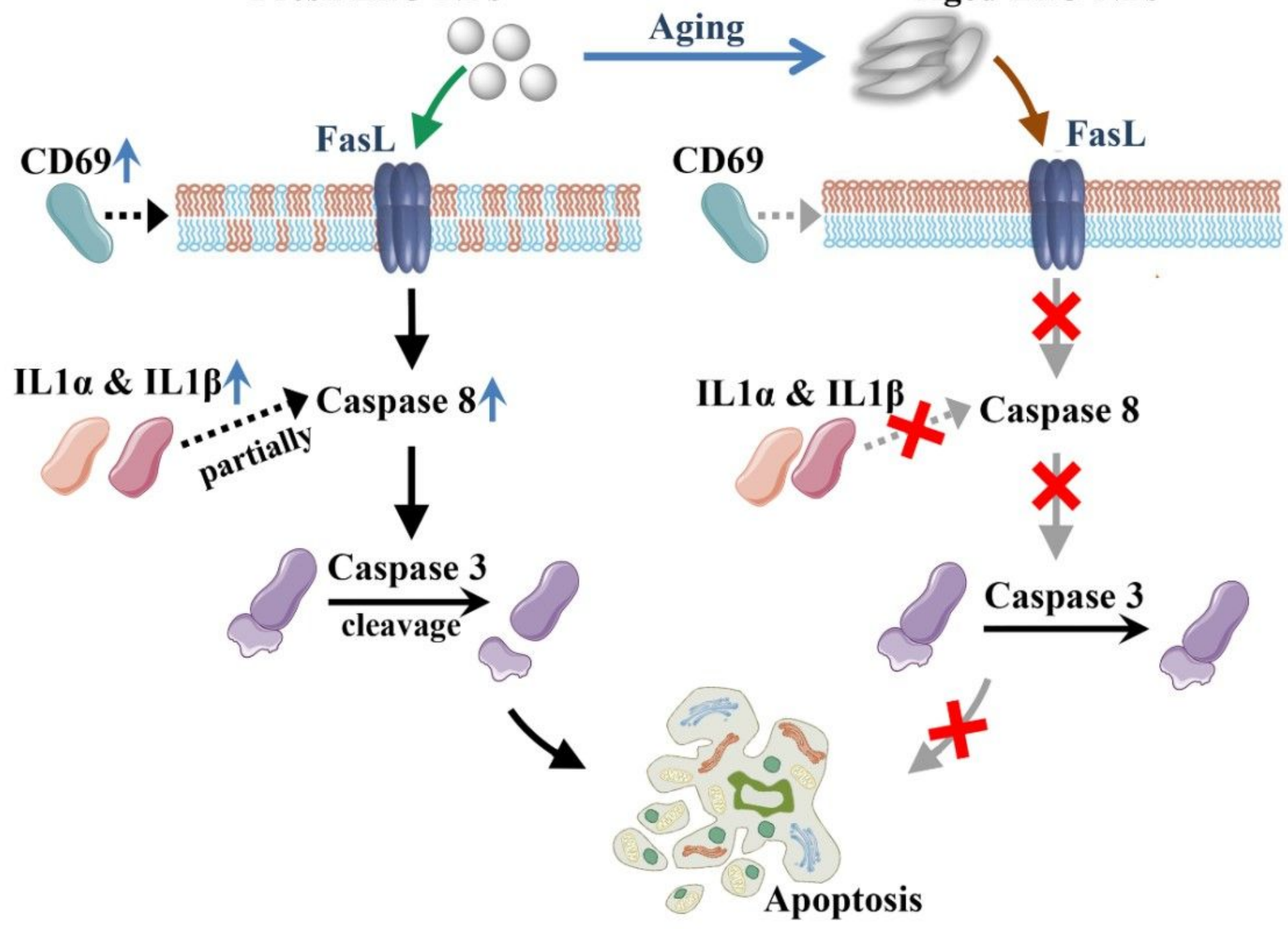

Figure 7

Model for Fresh ZnO NPs but not aged ZnO NPs induces Caspase 8- and Caspase 3- dependent apoptosis. The increased expression of apoptotic gene CD69 activates Fas and apoptosis annexin V expression in fresh ZnO NP-exposed mammalian cells. The increased expression of apoptotic gene IL1a andIL1 $\beta$ partially activates Caspase 8-dependent apoptosis. It further causes activation of Caspase 3 and induces apoptosis. All these changes in mRNA and protein level were not detectable in aged ZnO NPsexposed mammalian cells. 